Aletheia, vol. 10, $\mathrm{n}^{\circ}$ 20, e052, junio-noviembre 2020. ISSN 1853-3701

Universidad Nacional de La Plata

Facultad de Humanidades y Ciencias de la Educación

Maestría en Historia y Memoria

\title{
Cambiar las políticas de memoria
}

Changing memory policies

\section{Wanda Wechsler}

Universidad Nacional Arturo Jauretche (UNAJ),

Núcleo de Estudios Judios (NEJ) e Instituto de Desarrollo Económico y Social Grupo (IDES), Argentina

wandaprofesores@gmail.com

\section{RESUMEN:}

En los últimos cuatro años, el gobierno de Cambiemos ha realizado un giro en las políticas de memoria y de educación en Argentina. Extendiendo a nivel nacional ciertas políticas ya presentes en la Ciudad de Buenos Aires, con el triunfo de Mauricio Macri en el gobierno nacional y la asunción de Claudio Avruj a la Secretaría de Derechos Humanos y Pluralismo Cultural, se visibilizó a través de acciones y discursos una transformación del área. El presente artículo analiza este giro del período, observando cómo se privilegió cierto discurso mientras se buscó desarmar el construido por los gobiernos kirchneristas. Mientras se le quitó presupuesto a los sitios de memoria, archivos e investigadores, se establecieron fuertes lazos con quienes construyen la memoria del Holocausto en el país. Estas políticas mostraron además los lazos de Cambiemos con un sector de la comunidad judía local.

Palabras Clave: Memorias, Holocausto, Derechos Humanos, Educación.

\section{Abstract:}

In the last four years, the government of Cambiemos has made a turn regarding memory and education policies in Argentina. With the electoral triumph of Mauricio Macri and rise to the Secretary of Human Right and Cultural Pluralism of Claudio Avruj, certain policies, already enacted in the City of Buenos Aires, were extended to the national level, and, consequently, a transformation of this particular area was witnesses, due mainly to actions and speeches. Therefore, this article analyzes this turn, observing how a specific discourse on memory was promoted, while another, built by the Kirchnerist goverments, was disarmed. While memory sites, archives and researchers suffered budget cuts, strong ties were established with those who build the memory of the Holocaust in the country. These policies also showed Cambiemos and a certain sector of the local Jewish community.

KeYWORDs: Memories, Holocaust, Human rights, Education.

\section{Los PRIMERos PASOS DEL GIRO DE CAMBIEMos}

El 10 de diciembre del 2015 asumió el gobierno de Cambiemos liderado por Mauricio Macri, luego de un balotaje, y puso fin al predominio político del kirchnerismo de los últimos doce años. Como afirma el trabajo de Barros y Morales ${ }^{1}$, desde la campaña electoral se proponían un "cambio" de rumbo en la política nacional que también abarcaba una revisión del tratamiento de los derechos humanos de la última década. Un giro al respecto se evidenció en el discurso a través de una serie de declaraciones. De forma provocadora y en un tono anacrónico de la Teoría de los Dos Demonios ${ }^{2}$, elaboraron afirmaciones sobre las diversas maneras de reconocer e intentar beneficiar a los represores y cuestionaron las políticas de memoria realizadas durante el período kirchnerista. Algunas de estas políticas fueron la anulación de las leyes de Obediencia Debida y Punto Final dictadas por Raúl Alfonsín durante los años ochenta, la reapertura de los procesos judiciales contra personas involucradas en la represión ilegal, la derogación del decreto de prohibición de extradición de militares argentinos y la ratificación del convenio internacional sobre la imprescriptibilidad de los crímenes de guerra y lesa humanidad. Otro hecho relevante de las políticas de memoria del período kirchnerista fue la creación del Registro Unificado de Víctimas del Terrorismo de Estado (Ruvte) de la Secretaría de Derechos 
Humanos, que elaboró una matriz de datos de alcance nacional -de actualización constante- sobre las víctimas del terrorismo de Estado y de los centros clandestinos de detención y otros lugares de reclusión.

Para comprender las nuevas políticas de memorias implementadas desde el año 2015, un primer hecho relevante fue la sanción del decreto 64/2016 en enero de 2016, por el que se renombró la Secretaría de Derechos Humanos como "Secretaría de Derechos Humanos y Pluralismo Cultural” y se designó a Claudio Avruj a cargo. A partir de este momento y de diversas formas se realizaron una serie de afirmaciones que cuestionan las políticas de memoria anteriores. Un ejemplo de esto se observa en una entrevista realizada por el diario Clarín en la que se preguntó al Secretario de DDHH y Pluralismo Cultural de Cambiemos Avruj, “¿Cuánto dinero ha dado el Estado en indemnizaciones a víctimas del terrorismo de Estado?”. Al respecto afirmó que durante el gobierno de Cristina Kirchner realizó un uso exagerado de las reparaciones: "habilitó a tener un resarcimiento económico a todos aquellos que demuestren haber sido privados de libertad desde 1955 hasta 1983, por cualquier causa política. Eso abrió a un universo gigantesco. Pero lo más grave, quizás, es que lo que se ha pagado, que son cerca de 30.000 millones, pero que todavía hoy tenemos en carpetas de investigación más de 27.000 expedientes, habiendo nosotros procesado ya 12.000 en nuestros cuatro años" ${ }^{3}$. Esta mirada sobre el pasado evidenció un aspecto de este giro en las políticas de memoria.

Otras afirmaciones que generaron polémicas fueron en torno al número de desaparecidos ${ }^{4} \mathrm{y}$ un intento discursivo que buscó separar la política de la memoria. Pero quizás más evidente resulta el hecho de que desde la Secretaría, durante los primeros meses de su gestión, se llevó adelante una ola de despidos y de recortes presupuestarios en organismos del Estado a las dependencias vinculadas a los derechos humanos, afectando particularmente a las áreas que se ocupan de las causas por crímenes de lesa humanidad y a la implementación de políticas públicas en torno a los ejes de verdad, memoria y justicia 5 . De esta manera se llevó adelante un proceso de achicamiento de presupuesto y recursos para el mantenimiento de los sitios de memoria ${ }^{67}$.

Un ejemplo de la transformación en los sitios se evidenció desde el año 2016 en el Centro Cultural de la Memoria Haroldo Conti, que se encuentra ubicado en el predio donde funcionó durante la última dictadura cívico-militar (1976-1983) uno de los Centros Clandestinos de Detención, Tortura y Extermino más emblemático: la Escuela de Mecánica de la Armada (ESMA) ${ }^{8}$. Ya por ese entonces, los y las trabajadoras realizaban un reclamo en torno al paulatino desfinanciamiento del espacio, bajo la campaña "el Conti no se achica". En ese momento Avruj ya afirmaba que el presupuesto de este espacio estaba "sobreestimado" (Perfil, 1-10-16) y que en pos de "trasparentar" debieron "reestructurar las partidas".

También al respecto la presidenta de la comisión de DDHH de la cámara de diputados Victoria Montenegro se pronunció en torno a la grave crisis que sufrían los sitios dependientes del Archivo de la Memoria. Los ex centros clandestinos de detención que se encuentran en esta situación dependen de forma directa del Archivo de la Memoria, un organismo descentralizado dependiente de la Secretaría de DDHH y Pluralismo Cultural, que quedó a cargo de Sergio Kuchevasky ${ }^{9}$. Cuatro de los seis sitios en este estado se encuentran en la Ciudad de Buenos Aires: Club Atlético, Virrey Cevallos, Orletti y el Olimpo (a ellos se suman dos en el interior: El Faro de Mar del Plata y la Escuelita de Famaillá, en Tucumán).

\section{¿Qué Memorias busca Promover el gobierno de Macri?}

Desde la llegada del gobierno de Cambiemos al gobierno nacional, las declaraciones y acciones en torno a los DDHH mostraron su interés de revisar las políticas de memoria. Este nuevo paradigma denunciaba abusos y "curros" realizados por los gobiernos anteriores en materia de DDHH y una apropiación demagógica ${ }^{10}$. Esta nueva mirada sobre las memorias y el pasado puede ser considerada como una reorientación en búsqueda de la "deskirchnerizacion" de los DDHH, la creación de una mirada apolítica y no partidaria de las memorias y la reorientación de la Secretaría con un enfoque en la promoción de las libertades y derechos individuales. 
Sin embargo esta supuesta mirada apolítica del pasado incluyó la búsqueda por pluralizar la causa de los derechos humanos, distanciando la causa de los derechos humanos con el terrorismo de Estado. Avruj afirmó que "El compromiso nuestro en derechos humanos va mucho más allá de memoria, verdad y justicia, que lo tenemos en el centro de la política de derechos humanos [...] Hemos empezado un trabajo de visita a los presos penitenciarios para trabajar de cerca en el cuidado de la cárceles; violencia de género, institucional, acceso a la justicia, medioambiente, pluralismo cultural y diversidad sexual forman parte de una gama de derechos humanos a desplegar que nos tienen que posicionar en un buen presente y mucho mejor hacia el futuro" 11 .

El discurso vinculado al pluralismo no significó la ausencia de políticas de memoria sobre el terrorismo de Estado y los años setenta. Se evidenció un acercamiento entre las fuerzas armadas y el gobierno de diferentes maneras. Por un lado durante el año 2016, Avruj realizó una serie de encuentros con la organización de familiares de víctimas del terrorismo nucleadas en torno al "Centro de Estudios Legales sobre el Terrorismo y sus Víctimas (CELTYV)”. Distanciándose de las políticas de los gobiernos kirchneristas, se buscó un acercamiento a los familiares víctimas de la guerrilla durante los años setenta ${ }^{12}$.

Por otro, durante los primeros meses del gobierno de Cambiemos, comenzaron a difundirse ideas sobre un cierre definitivo del trauma del pasado, y que proyectan sus expectativas de olvido, perdón y reconciliación en un futuro promisorio. Tales versiones ya existían durante los años anteriores, pero tomaron fuerza en los meses transcurridos desde el inicio de la nueva gestión. En este clima, en mayo de 2017, la Corte Suprema realizó una acción sorpresiva que puso en jaque toda una política de Estado de los años anteriores. Las firmas de los dos jueces designados por Macri - Carlos Rosenkrantz y Horacio Rosatti- sumado al aval de la jueza Elena Highton de Nolasco ${ }^{13}$, permitieron que el represor Muiña consiguiera para sí el beneficio que preveía la vieja ley del $2 \times 1$, que consiste en computar dobles los días de prisión preventiva pasados los dos años sin sentencia ${ }^{14}$. Muiña operó durante la última dictadura cívico-militar en el Hospital Alejandro Posadas, donde funcionó un centro clandestino de detención. Con una lectura forzada de la ley, se intentó generar un cambio de argumentos que abría una compuerta a los acusados de crímenes de lesa humanidad. Este accionar de la corte suprema generó un público repudio por parte de los organismos de DDHH y una gran movilización popular el 10 de mayo de 2017 que concluyó en Plaza de Mayo.

Por último, otro hecho que muestra el acercamiento fue la presencia de militares en desfiles y actos nacionales. Un ejemplo se evidenció en el acto del 9 de julio de 2019, día de la Independencia Argentina, en el cual se realizó un desfile militar que tuvo la presencia de militares que integraron el grupo "Carapintadas" 15. La presencia de estos militares fue minimizada por el ministro de defensa Oscar Aguad: "Lo de los carapintadas es cosa vieja. Fue un acontecimiento chiquito, que yo no creo que haya puesto en jaque a la democracia", dijo.

Mientras el gobierno construyó una política de la memoria que intentó beneficiar a los represores, cuestionando las políticas de los organismos de $\mathrm{DDHH}$ y de los anteriores gobiernos, reduciendo el presupuesto destinado a los archivos y sitios memoria, elaboró otras políticas de la memoria que vale la pena atender. En el plano simbólico y estratégico, ha apostado en los últimos años a visibilizar la memoria del Holocausto y darle un lugar especial en la agenda política nacional.

Desde el comienzo de la presidencia (2015), Macri ha asistido y dado discursos en los actos del Día Internacional de la Conmemoración en Memoria de las Víctimas del Holocausto, los días 27 de enero. También, como se adelantó, ha nombrado como secretario de Derechos Humanos y Pluralismo Cultural de la Nación a Avruj, referente de un sector la comunidad judía argentina y entonces presidente del Museo del Holocausto de Buenos Aires. Ese cargo fue ocupado luego por Gustavo Sakkal, un allegado a Avruj y en la actualidad lo tiene Marcelo Mindlin, empresario argentino dueño de Pampa Energía y mano derecha del presidente de la Nación. La llegada de Mindlin al museo ha permitido realizar una reforma profunda en términos edilicios y de contenido en el Museo ubicado en la calle Montevideo. El Museo del Holocausto de Buenos Aires reabrirá sus puertas en diciembre de este año con una nueva muestra de mayor envergadura ${ }^{16}$. 
La cercanía del gobierno nacional con algunos referentes del sector representante de las instituciones de la comunidad judía argentina puso en un primer lugar el desarrollo de la memoria del Holocausto. Tanto Avruj como Mindlin son actores claves en el desarrollo del gobierno y muy cercanos al presidente.

\section{¿QUIÉNES SON ESTOS ACTORES?}

Es interesante revisar las trayectorias de los actores allegados al macrismo que ocuparon y ocupan hoy cargos importantes para visibilizar la memoria del Holocausto. Acceder a sus trayectorias nos permite conocer sus posiciones y prácticas, sus pensamientos y recorridos, para acercarnos a la disponibilidad de los capitales tanto social, cultural como económicos. Nos resulta interesante pensar a los sujetos como parte de un colectivo mayor, no como individuos, que se mueven en una estructura en red. Retomando el concepto de Bourdieu, la noción de trayectoria es pensada como "serie de las posiciones sucesivamente ocupadas por un mismo agente (o un mismo grupo) en un espacio en sí mismo en movimiento y sometido a incesantes transformaciones" 17 . Reconstruir las trayectorias de los sujetos, a través de sus recorridos políticos e institucionales, supone no solo la enumeración de cargos, sino un análisis de las redes de relaciones y posiciones establecidas, que ayudan a comprender las acciones llevadas a cabo por el gobierno de Cambiemos.

Comencemos por Avruj, quien ocupó el cargo de presidente del Museo desde el año 2013 hasta el 2015. Anteriormente fue funcionario de Rubén Beraja ${ }^{18}$, ex presidente del Museo (1998), fue Secretario de la DAIA (1999) y Director Ejecutivo entre 1997 y 2007. Avruj abandonó el puesto en la DAIA para ser subsecretario de derechos Humanos del GCBA en el año 2010, bajo el gobierno de Mauricio Macri, tras la salida de Edgardo Berón. También había ocupado el cargo de director general de Relaciones Institucionales del Pro desde el año 2007.

En su carrera profesional Avruj es licenciado en dirección y organización institucional de la Universidad Bar Ilan, cuyo propietario era Beraja. En el ámbito de las Organizaciones no Gubernamentales, Avruj trabajó en la fundación "Creer y Pensar" e invirtió en "Minuto 91", una productora de programas de radio y TV de Gustavo Szpigiel, realizado desde las oficinas en la sociedad Hebraica Argentina. También formó una sociedad con el periodista Guillermo Yanco, marido de Patricia Bullrich e integrante activo del Museo del Holocausto. Juntos llevaron adelante el emprendimiento $V I S$ a $V I S$, que tiene programas de televisión, radio y un portal de noticias judías, auspiciado por publicidades del Gobierno de la Ciudad y entidades como el Banco Ciudad, Telecom Argentina e IRSA. Al ingreso de Avruj al Museo, Yanco pasó a ocupar un lugar central adentro del museo, donde sigue trabajando hasta la actualidad (2019).

Un segundo actor importante es Marcelo Mindlin, presidente del Museo desde el 2017 hasta la actualidad (2019). Empresario argentino, hizo crecer su patrimonio de manera exponencial en los últimos cuatro años. Según la revista Forbes se ubica en los primeros puestos de los 50 más ricos de la Argentina, junto con la familia Macri y Caputo. En un contexto complicado de crisis económica y endeudamiento estatal, Mindlin ha incrementado su patrimonio en parte gracias a los incrementos de tarifas de los últimos cuatro años y la concentración de empresas energéticas y de gas en su apellido, como Edenor, Transener, TGS. La empresa Pampa Energía pasó de estar en el puesto 103 en el ranking de las empresas que más facturan en el país, al puesto 10, también según la revista Forbes.

Su carrera profesional la realizó en la UBA, cursando Economía y recibiéndose en el año 1988. Desde fines de los ochenta se dedicó al mundo empresarial, invirtiendo y comprando diversos negocios, en general vinculados a los servicios como luz, gas, petróleo. A la vez, desarrolló su lado filantrópico, al ser presidente de la Tzedaká, fundación benéfica de la comunidad judía fundada a principios de los años noventa donde todavía se desarrolla como presidente honorario de la institución. A partir del 2017 asumió el cargo de presidente del Museo del Holocausto de Buenos Aires y en medio de una profunda crisis económica y edilicia del museo, Mindlin impulsó una reforma total del edificio ubicado en la calle Montevideo, trasladando en una sede provisoria el museo al Seminario Rabínico. 


\section{¿DE QUÉ Formas SE BUScó visibilizar la memoria del Holocausto?}

Se puede observar que desde la llegada de Macri al poder en la Ciudad de Buenos Aires en el año 2007, se fueron tejiendo lazos entre la institución Museo del Holocausto y el gobierno local y nacional. En la ciudad en particular y desde la Secretaría de Cultura, se llevó adelante una política cultural denominada la "Noche de los Museos". Esta iniciativa visibilizó varios museos, entre los cuales se destacó el Museo del Holocausto. Retomando el anterior apartado, se demostró una relación concreta entre los “emprendedores", utilizando el término de Elizabeth Jelin (2002), de la memoria del Holocausto y algunos integrantes del partido político Cambiemos. Esto se refleja por ejemplo en la presencia y participación en los actos conmemorativos vinculados al Holocausto que realiza el Museo de políticos integrantes del partido. Un ejemplo reciente, entre muchos otros, fue la noche de presentación del proyecto de reapertura del museo (30-10-18), realizada en el Centro Cultural Kirchner, estuvieron presentes el rabino Sergio Bergman, ministro de Medio Ambiente integrante de Cambiemos, el jefe de la Ciudad de Buenos Aires Horacio Rodríguez Larreta, representante de Cambiemos, Hernán Lombardi, quien ocupó diversos cargos junto a Mauricio Macri, como el de ministerio de Cultura de Buenos Aires y también Miguel Angel Picheto, candidato a vicepresidente en la fórmula de Cambiemos $2019^{19}$.

Otro dato relevante es que en el año 2016, se estableció un acuerdo entre el Museo del Holocausto y el gobierno de la Ciudad para que la Policía Metropolitana que responde a la Ciudad de Buenos Aires, visite todos los años el espacio en el marco de la capacitación en derechos humanos que desarrolla el Instituto Superior de Seguridad Pública.

Un suceso más reciente fue la entrega por parte del Ministerio de Seguridad al Museo de una serie de objetos nazis ${ }^{20}$ como depositario judicial, en el marco de la causa caratulada como "Olivares, Carlos Alberto sobre infracción de la ley 25.743”. Realizado por la ministra de seguridad Patricia Bullrich, se llevó a cabo un acto de entrega junto al presidente del Museo, Mindlin, la jueza a cargo de la causa Sandra Arroyo Salgado y el jefe de la Policía Federal Argentina Néstor Roncaglia. Tanto en el acuerdo realizado con la policía Metropolitana como en la entrega de los objetos nazis, cumplió un rol central la ministra de seguridad Patricia Bullrich, quien como se comentó anteriormente, además es la esposa de Yanco, vicepresidente del Museo del Holocausto.

También durante el cargo de jefe de gobierno de Macri, el Museo fue declarado "Sitio de interés cultural" en el 2006 por la Legislatura. Además de hacerse visibles y construir la relación entre el Museo y el gobierno, también se evidenciaron en los últimos años otros hechos significativos. Durante el período 2013- 2014 se edificó en la Ciudad la Plaza de Homenaje a las Víctimas del Holocausto-Shoá y se puso en marcha la construcción de un monumento dedicado a las víctimas. Este monumento finalmente se inauguró en el 2016, ya con Cambiemos como gobierno nacional y el acto estuvo a cargo de la Secretaría de Derechos Humanos y Pluralismo Cultural de la Nación, en el marco del Día Internacional de Conmemoración Anual en Memoria a las Víctimas del Holocausto. De este acto participaron Avruj, Pablo Avelluto, ministro de Cultura de la Nación desde el 2015, Horacio Rodríguez Larreta, Sergio Bergman y sobrevivientes, familiares y representantes de algunas organizaciones de la comunidad judía, como el entonces presidente de la DAIA, Ariel Cohen Sabban. Es interesante que, aunque el proyecto de monumento fue impulsado muchos años antes, en el 1996, por el diputado Claudio Mendoza y en el año 2000 recién se dispuso la realización de la obra, no se logró realizar hasta la llegada del PRO al poder, quienes finalmente lo inauguraron, aunque la obra fue entregada durante la presidencia de Cristina Kirchner en febrero del 2015.

Otro evento relacionado a la memoria del Holocausto promovido por el gobierno nacional fue la apertura del primer archivo público por la memoria del Holocausto del país, durante junio de este año. El denominado Fondo Simón Wiesenthal fue promocionado por el Centro que lleva el mismo nombre, junto con el Museo del Holocausto y Generaciones de la Shoá. Este archivo, incluye textos de divulgación sobre el antisemitismo, investigaciones sobre los nazis que pasaron por Argentina y testimonios de sobrevivientes del Holocausto. 
También algunas investigaciones sobre xenofobia y racismo y algunos textos de ficciones. Está ubicado en la Biblioteca Nacional y se puede visitar de forma gratuita. Este proyecto se concretó gracias al lazo entre Ariel Gelblung, director de Centro Wiesenthal y Alberto Mangel, anterior director de la biblioteca. Tanto el Museo del Holocausto como la Amia fueron donantes de este archivo. Lo interesante de la creación de este archivo es que durante el 2015 se elaboró una propuesta muy similar por parte del gobierno nacional que presidía Kirchner en la Biblioteca del Maestro, lo que será ampliado más adelante.

De esta manera el gobierno de Cambiemos estableció lazos con representantes de la construcción de la memoria del Holocausto en Argentina, como Avruj, Midlin o Gelblung. A la vez, fomentó la visibilización de esta memoria y le otorgó un lugar preferencial en el espacio público. No parece casualidad que además los cargos vinculados a políticas de memoria y derechos humanos hayan sido otorgados a referentes de la comunidad judía local como Claudio Avruj, secretario de Derechos Humanos y Pluralismo Cultural de la Nación, Sergio Kuchevasky, presidente del Archivo Nacional de la Memoria o Ariel Gomplewicz, director nacional de Sitios de Memoria, entre otros. A medida que las políticas de la memoria fueron realizando un giro, dando voz a los militares, promoviendo medidas de flexibilización de las condenas a los genocidas y quitando recursos a los sitios de memoria, se ocuparon de visibilizar y hacer crecer la memoria y representación del Holocausto y su presencia en el espacio público.

\section{Privilegiar en términos SIMbólico...Pero, ¿Y EN TÉrminos ReALEs?}

El gobierno de Cambiemos ha realizado una serie de transformaciones en las prioridades vinculadas a las políticas de la memoria. En el caso de las que se vinculan con el Holocausto, se visibilizaron y se hicieron más concretos los lazos con la institución Museo del Holocausto y sus representantes. Se puede entender esta política como parte de una estrategia: impulsar y acompañar esta memoria tiene un efecto sobre cierto sector de la población, sobre todo sobre aquel sector de la comunidad judía local perteneciente a las instituciones más representativas, como AMIA y DAIA, e implica un gesto de complicidad. También es una decisión política que posiciona al país en eje con convenciones internacionales y diálogo con otros países. De una forma similar a la que en Estados Unidos se institucionalizó, y en profundidad lo analizó Peter Novick (2007), comprometerse con la construcción de esta memoria en realidad no compromete nada, y sobre todo si no se hace apuntando a combatir la xenofobia y la exclusión tan presentes en la actualidad. Con el apoyo a las instituciones Cambiemos parece querer garantizar una ética propia del orden occidental. Como trabajó Traverso (2014) una de las consecuencias del declive del antisemitismo a nivel mundial fue la reconciliación entre sectores políticos de derecha y algunos sectores pertenecientes a la comunidad judía.

Por otro lado, y aunque excede el presente artículo, la creación y establecimiento de estos lazos con los representantes de la comunidad judía institucionalizada puede entenderse como una estrategia que forma parte de las relaciones internacionales. El posicionamiento de Argentina como un país aliado de Israel y las buenas relaciones establecidas fueron evidenciadas en los encuentros entre los dirigentes de ambos países ${ }^{21}$.

Es interesante remarcar que si bien las políticas de memoria de Cambiemos han buscado privilegiar el recuerdo del Holocausto, haciendo presencia en actos conmemorativos, inaugurando plazas, estableciendo relaciones con el Museo del Holocausto y fomentando sus vínculos con quienes detentan hoy su memoria oficial, esto no implica que en los gobiernos anteriores no se hayan realizado políticas memoriales.

Si revisamos las políticas de educación y memoria referidas al tema del período kirchnerista, se encuentra un desarrollo particular. Como han trabajado Emmanuel Kahan y Celeste Adamoli (2017), el Holocausto fue incluido en la agenda educativa y se construyó un problema pedagógico en torno a su enseñanza. Se produjeron materiales educativos y se activó la formación docente de maestros y maestras de nivel primaria y secundaria. Desde el año 2005 el Ministerio de Educación de la Nación desempeñó una política educativa de memoria que tuvo como centro la promoción de la historia reciente. Para esto produjeron materiales específicos nuevos, debatieron y acompañaron transformaciones curriculares y crearon cursos de formación 
docente a nivel nacional. Durante el 2006 se sancionó la Ley de Educación Nacional № 26.206 que estableció en su capítulo "La calidad educativa" que formarán parte de los contenidos curriculares comunes de todas la jurisdicciones el ejercicio de la construcción de la memoria colectiva sobre los procesos históricos y políticos que quebraron el orden constitucional instaurando el terrorismo de Estado, con el objeto de generar en los alumnos reflexiones y sentimientos democráticos y el compromiso con el Estado de Derecho y la plena vigencia de los Derechos Humanos. Esta normativa se complementó con disposiciones específicas nacionales y en el 2009 el Consejo Federal de Educación aprobó la Resolución número 80/09 titulada "Plan de Enseñanza del Holocausto" que comprometió a los ministerios nacional y provinciales a la realización de acciones concretas para la inclusión curricular y la enseñanza de esta temática. Posteriormente en el año 2012 el Consejo Federal de Educación aprobó la Resolución 180/12 que propiciaba la enseñanza del Holocausto/Shoá y otros genocidios del siglo XX en el ámbito de la educación secundaria. Finalmente, la Resolución 269/15 creó la "Red Nacional de Educación y Memoria" reafirmado que la educación en la memoria constituye un aporte fundamental en la construcción de una sociedad más justa con una ciudadanía activa en la defensa de los derechos humanos.

Otro dato interesante es que en el año 2007 el Ministerio de Educación de la Nación organizó, junto al denominado "capítulo local" de la Alianza Internacional por el Recuerdo del Holocausto (IHRA) ${ }^{22}$, un seminario internacional que resultó inaugural para el armado posterior de las propuestas educativas en torno al Holocausto: "La enseñanza del Holocausto/Shoá como acontecimiento clave del siglo XX. Aportes para una agenda educativa en tiempo presente" ${ }^{23}$. Esto se realizó como parte de un compromiso internacional asumido por el Estado argentino y estableciendo vínculos con organismos mundiales.

En aquel momento (2007) las políticas de educación y memoria ya tenían algunos años de desarrollo. El proyecto inicial que posteriormente fue consagrado como "Programa Nacional", surgió inicialmente a propósito de las conmemoraciones de los treinta años del golpe de 1976. El punto de partida fueron algunos antecedentes y discusiones del ámbito educativo y académico que desde los años ochenta en adelante atravesaron el campo de los derechos humanos, las ciencias sociales y los procesos de conformación de la memoria colectiva. Asimismo, se trabajó sobre el reconocimiento de propuestas que ya funcionaban en las escuelas y eran promovidas por docentes a través de sindicatos o de modos más o menos solitarios, pero no por eso menos comprometidos con la enseñanza de temas de memoria.

Como se ha revisado fue el gobierno kirchnerista el que realizó desde el Ministerio de educación y las políticas de la memoria amplia gama de materiales educativos, entre los cuales se editaron "La Shoá en la pantalla" (2006), "Memorias en fragmentos: miradas sobre el holocausto" (2007) y "Holocausto: preguntas, respuestas y propuestas para su enseñanza" (2009) ${ }^{24}$. También se realizaron una serie de encuentros y seminarios de capacitación docente a nivel nacional e internacional, los cuales posicionaron a la memoria del Holocausto como referente local para pensar nuestro pasado. Además se incentivó la investigación y creación de materiales con propuestas didácticas para trabajar estos temas en las aulas, dando trabajo a especialistas en estos temas. Lo interesante es que al ser el Estado quien los creó, todos materiales fueron distribuidos en las escuelas del territorio nacional y fueron utilizados durante los espacios de formación docente que ofreció el Ministerio de Educación en cada una de las provincias argentinas. Esta formación federal contó con la presencia de reconocidos investigadores y académicos de distintas universidades nacionales y organismos internacionales dedicados a la investigación y enseñanza del Holocausto 25.

Otra innovación dentro del programa de formación docente fue en el año 2015 la creación de un curso virtual de capacitación en el marco del Plan Nacional de Formación Docente "Nuestra Escuela", sobre "Holocausto y genocidios en el siglo XX". Este curso posibilitó la capacitación de docentes alejados de los circuitos metropolitanos y, además, estableció un diálogo entre la formación propiamente histórica y conceptual con las tecnologías y los entornos virtuales. El curso tuvo, como experiencia innovadora, un "aula especial”, auspiciada por UNESCO, para la capacitación de funcionarios en el marco de la Red de puntos focales para América Latina sobre la enseñanza del Holocausto. 
Por último es que también en el 2015 se elaboró y presentó en la Biblioteca Nacional del Maestro un Fondo bibliográfico denominado "Memoria y Holocausto", que formó parte del Programa Educación y Memoria de la Subsecretaría de Equidad y Calidad Educativa Ministerio de Educación de Nación. Tenía como objetivo poner a disposición, visibilizar y promover el valor de los libros como resguardo de la memoria colectiva y el vínculo entre generaciones, asumiendo el complejo desafío de enseñar el Holocausto. Este fondo integró, además de libros de la temática, todas las publicaciones realizadas por el Programa Educación y Memoria del Ministerio de Educación durante esos años.

Como se observó durante los gobiernos kirchneristas se había logrado construir lazos entre el Estado y las instituciones judías además de fomentar, crear y difundir materiales didácticos, formaciones docentes y participar de actividades internacionales. Un gran paso en la democratización y divulgación de la memoria del Holocausto se evidenció en la creación y difusión de materiales desde el Estado, lo que garantizó su llegada a las escuelas públicas del país. Además, estos materiales formaron parte de un plan educativo que incluyó otras memorias, como las del Terrorismo de Estado o las de la guerra de Malvinas. De esta forma, la memoria del Holocausto dejaba de ser una memoria judía para convertirse en una memoria cosmopolita, universal y crítica.

En conclusión pensada como una política de estado e incluida en las políticas de memoria nacionales, el período 2003-2015 pudo pensar desde la ejemplaridad. Retomando un concepto de Todorov (2017), se realizó un "uso ejemplar" de este hecho histórico, ejerciendo su recuperación desde un recorte en el presente, que permita cuestionar y dar cuenta de otros genocidios. Fue por eso que desde el Estado se incorporó en ese período la enseñanza del Holocausto junto con otros hechos históricos como el terrorismo de Estado. Como afirman quienes participaron del armado de materiales, cursos y formaciones docentes en el período, "en el desarrollo de las políticas de educación y memoria, el tema del Holocausto se sostuvo en un doble registro: por un lado, en relación a la enseñanza y construcción del tema Holocausto como experiencia histórica concreta -genocidio cometido durante la Segunda Guerra Mundial-, pero también como un andamiaje teórico y un espejo para pensar la propia experiencia del terrorismo de Estado en Argentina. En este sentido, la memoria del Holocausto fue, como lo es en un contexto más amplio, un campo de referencia para abordar y pensar desde un conjunto de reflexiones sociológicas, históricas, filosóficas, políticas y sobre todo pedagógicas" (Adamoli, Kahan, 2017).

El reconocer que ese proceso traumático permite problematizar las memorias locales o ayudar a pensarlas fue un paso decisivo. Las heridas aún abiertas en Argentina, que por aquellos años comenzaban a encontrar un poco de lugar para ser procesadas, pudieron ser comprendidas y atravesadas a partir del prisma de un horror anterior. Así, acontecimientos lejanos en tiempo y en espacio permiten reconocer algunos más cercanos, nos hacen reflexionar sobre nuestro presente e invitan a estar alertas sobre problemas actuales como la xenofobia, la discriminación, la intolerancia, entre otros.

\section{Conclusiones}

A lo largo de este artículo nos propusimos analizar algunas de las políticas de la memoria realizadas durante los últimos cuatro años en la experiencia del gobierno de Cambiemos. Entendiendo estas políticas como un giro sobre las realizadas durante los gobiernos kirchneristas, se observó el distanciamiento en sus afirmaciones y acciones referidas a las víctimas del terrorismo, los sitios de memoria, las penas para represores, la presencia pública de militares carapintadas y las reuniones con una organización de familiares de víctimas del "terrorismo". Mientras se buscó transformar la relación entre el Estado y las construcciones previas sobre los derechos humanos, también se evidenció otro cambio. En los últimos cuatro años se forjó el acercamiento y el tejido de una red de relaciones entre algunos representantes del gobierno nacional con algunos representantes de la construcción de la memoria del Holocausto, pertenecientes a un sector de la comunidad judía local. 
Revistando las trayectorias de algunos dirigentes de esta comunidad, se evidenció la construcción de lazos y relaciones que siguen vigentes.

A la vez y para comprender cómo fueron pensadas las políticas de memoria vinculadas al Holocausto, se buscó revisar en este artículo las diversas formas en las que se ha incorporado a la memoria del Holocausto en los períodos 2003-2015 y 2015-2019 desde las políticas de educación y derechos humanos. En ambos períodos las memorias fueron recuperadas pero fue distinta su utilización. Se observó que, si bien en los últimos años se visibilizó más la memoria del Holocausto, fue durante los doce años de los gobiernos kirchneristas que se produjeron materiales, prácticas y políticas sobre esa memoria. Estos materiales no fueron retomados ni profundizados, ni se generaron nuevas estrategias de educación y formación.

Lo interesante es observar que la construcción de las memorias establece lazos locales, y sus usos varían según sus objetivos. Como puente para resaltar ciertos valores generales como los derechos humanos, el pluralismo, la tolerancia y el respeto por la alteridad, durante los últimos años de gobierno se ha utilizado a la memoria del Holocausto para que los políticos puedan presentarse como portadores y defensores de estos valores universales.

Se llevaron a cabo en estos últimos años prácticas ritualizadas en instituciones reconocidas, con testimonios de supervivientes, resaltando un "deber de memoria" que se convirtió en un discurso conformista, utilizado de manera ritual, que no cuestiona ni problematiza el pasado. A la vez las acciones y afirmaciones que emanaron del secretario de DDHH y Pluralismo Cultural permitieron desviar la atención y jerarquizar una memoria universal por sobre las memorias locales. Esta construcción de políticas de la memoria es por lo menos riesgosa. Centrada en sus testimoniantes, sus símbolos y procesos históricos, no permite reactivar otras experiencias históricas, ni otras víctimas y mucho menos otras memorias. Tampoco establece lazos con genocidios menos conocidos u olvidados, como se supo hacer en el período anterior.

La instauración de días de la memoria, la construcción de monumentos ${ }^{26}$, la inversión en museos y memoriales presenta una tensión: que la memoria se institucionalice, rigidice y sea un discurso oficial. Sin duda, la memoria del Holocausto tiene un potencial inigualable para reflexionar sobre el pasado y el siglo $\mathrm{XX}$, pero también sobre el presente y los peligros vinculados la xenofobia, racismo, la represión y las diversas formas de violencia.

Resulta necesario trabajarla, estudiarla y difundirla como una estrategia pedagógica para la no repetición. ¿Qué sucede cuando esta memoria se oficializa, se aísla y jerarquiza?, ¿cuáles son los riesgos de que la detenten los poderes dominantes? Resulta arriesgado establecer un culto del pasado disociándolo del pasado reciente y del presente, y hacer de la memoria un ejercicio acrítico y estático. También se debe alertar sobre el intento de hacer de la memoria un ejercicio apolítico: quizás eso evidencia todo lo contrario, ¿no es acaso un hecho político el querer distanciar la memoria de los partidos políticos? Si bien durante el período anterior al actual gobierno se establecieron materiales, recursos y formaciones tendientes a vincular la memoria del Holocausto, entendida como universal, y la memoria del terrorismo de Estado, entendida como regional, en los últimos años se profundizó una separación entre estas memorias y se fomentó un uso y construcción de materiales, espacios y recursos vinculados al Holocausto por parte de instituciones privadas, no estatales.

En su trabajo sobre los abusos de la memoria, Todorov (2017) nos invita a reflexionar sobre el culto a la memoria y sus riesgos. Uno de ellos es que puede ser utilizado para desentenderse del presente e ignorar las amenazas actuales. Otro es que sus practicantes se aseguran algunos privilegios en el seno de la sociedad. Haber sido víctimas da derecho a quejarse, a protestar y a pedir. Con estos riesgos, resulta un desafío de aquí en adelante construir memorias que logren enlazar diversos tiempos y espacios para profundizar una mirada crítica sobre la defensa de los derechos humanos hoy. Conservar ciertas memorias se hace necesario para alertar sobre situaciones nuevas, actuales y, sin embargo, análogas con varias del pasado. La construcción de las memorias tiene diferentes tiempos y ritmos, y pueden tener contramarchas. Es responsabilidad de las políticas de memoria del próximo gobierno poder elaborar nuevas formas de pensar nuestro pasado, incorporando experiencias, recursos e instituciones. Si bien no hay una memoria única de los hechos históricos, sí se suelen 
construir voceros oficiales. Sería interesante apostar a romper ciertos monopolios y dar lugar a nuevas voces, para que las memorias puedan cruzarse y el pasado pueda ser puesto al servicio del presente.

\section{ReFERENCIAS}

Adamoli, C.; Farías, M. y Flachsland, C. (2015). “Educación y memoria. La historia de una política pública”. Historia de la Educación. Anuario SAHE, Vol. 16 (2). Disponible en: http://ppct.caicyt.gov.ar/index.php/anuario/art icle/view/8386

Adamoli, C.; Kahan, E.(2017). "El abordaje del Holocausto desde la trama educativa: consideraciones sobre la construcción de una política de educación y memoria". Aletheia, volumen 7 , número 14 . Disponible en: http://www.aletheia.fahce.unlp.edu.ar/numeros/numero-14/dossier/el-abordaje-del-holocausto-desde-la-t rama-educativa-consideraciones-sobre-la-construccion-de-una-politica-de-educacion-y-memoria

AA.VV. (2007). Memorias en Fragmentos: miradas sobre el Holocausto. Buenos Aires: Ministerio de Educación de la Nación. Disponible en: http://repositorio.educacion.gov.ar:8080/dspace/handle/123456789/94811

AA.VV. (2010). La enseñanza del Holocausto/Shoá como acontecimiento clave del siglo XX. Aportes para una agenda educativa en tiempo presente. Buenos Aires: Ministerio de Educación de la Nación. Disponible en: http://ww w.bnm.me.gov.ar/giga1/documentos/EL005251.pdf

Baer, A. (2006). Holocausto. Recuerdo y representación. Madrid: Losada.

Baer, A., Sznaider, N.(2017) Memory and Forgetting in the post-Holocaust Era. Oxon: Routledge.

Bourdieu, P.(1977). La ilusión Biográfica. Razones prácticas. España: Anagrama.

Feierstein, D.(2018). Los Dos Demonios (recargados). Buenos Aires: Marea.

Grassi, L.; Novomisky, S.; Schenquer, L.; Vecslir, L. (2008). "Una reflexión sobre la importancia de la enseñanza de la shoá en Argentina”. Question, Volumen 1, número 18. Disponible en: https://perio.unlp.edu.ar/ojs/index.p $\mathrm{hp} /$ question/article/view/535

Huyssen, A. (2002). En busca del futuro perdido. México, D.F: Fondo de Cultura Económica.

Jelin, E. (2002). Los trabajos de la memoria. Buenos Aires: Fondo de Cultura Económica.

Kahan, E. y Lvovich, D. (2016) "Los usos del Holocausto en Argentina. Apuntes sobre las apropiaciones y resignificaciones de la memoria del genocidio nazi”. Revista Mexicana de Ciencias Politicas y Sociales. Vol. 61 (228). Disponible en: http://www.revistas.unam.mx/index.php/rmspys/article/view/56982

Novick, P. (2000). The Holocaust in the American Life. Boston-NY: Houghton Mifflin Harcourt.

Todorov, T. (2017). Los abusos de la memoria. Barcelona: Paidós.

Traverso, E. (2015). El fin de la modernidad judia. Historia de un giro conservador. Buenos Aires: Fondo de Cultura Económica.

Traverso, E. (2011). El pasado, instrucciones de uso. Buenos Aires: Prometeo Libros.

Traverso, E. (2012). La historia como campo de batalla. Buenos Aires: Fondo de cultura económica.

Wechsler, W. (2017). ¿Todo está guardado en la memoria? La memoria del Holocausto en Argentina a través de un Museo (1993-2013). Tesis de Maestría en Investigación Histórica. Universidad de San Andrés.

\section{Notas}

1 http://bdigital.uncu.edu.ar/objetos_digitales/8597/07-barros-esc14-2016.pdf

2 En su último trabajo Feierstein aborda una versión recargada de la "Teoría de los Dos Demonios" que primó en los años ochenta, en la cual el objetivo de la dualidad es hacer visibles a las "víctimas negadas", es decir aquellas que sufrieron la violencia insurgente calificada errónea pero intencionalmente como "terrorista". En este trabajo presenta las innovaciones y la peligrosidad de una versión que denomina re-cargada. Véase Feierstein, D. (2018). Los dos demonios (recargados), Marea, Buenos Aires. 
3 Avuj en Clarin, 27-07-19. https://www.clarin.com/politica/claudio-avruj-reclamo-familiares-victimas-guerrilla-legiti mo_0_ukq5DZK89.html

4 Algunos de estos dichos fueron retomados en las siguientes notas periodísticas: La Nación, 11-08-16; El Cronista, 24-03-17. https://www.cronista.com/economiapolitica/Avruj-sobre-los-desaparecidos-El-Nunca-mas-indiscutible-m arca-8500-personas-20170324-0087.html / https://www.lanacion.com.ar/politica/macri-evito-precisar-la-cifra-de-de saparecidos-y-genero-rechazos-nid 1926868

5 Para profundizar: http://bdigital.uncu.edu.ar/objetos_digitales/8597/07-barros-esc14-2016.pdf

6 Se denomina "Sitio de Memoria" a aquellos lugares que funcionaron como centros clandestinos de detención o donde sucedieron hechos emblemáticos vinculados al accionar terrorista por parte del Estado. https://www.argentina.gob.ar /derechoshumanos/sitiosdememoria

7 Para profundizar: https://www.pagina12.com.ar/3102-contra-el-vaciamiento-de-la-memoria

8 En el marco de las políticas de memoria realizadas durante el gobierno de Néstor Kirchner se creó el "Espacio para la Memoria y para la promoción de los Derechos Humanos" (ex ESMA) en el año 2004 mediante un decreto presidencial en el que se estipuló el desalojo de la Armada para la creación de un lugar en el que se elaborase y transmitiese el pasado reciente, cuya gestión quedó en manos de los organismos de derechos humanos y de distintos estamentos del Estado. Para profundizar sobre este espacio, leer la tesis doctoral titulada: "El predio: espacio y visualidad en el 'Espacio para la Memoria y para la Promoción y Defensa de los Derechos Humanos, ex ESMA (2004-2015)” de Florencia Larralde Armas.

9 Tanto Claudio Avruj como Sergio Kuchevasky, fueron denunciados ante el juez Ariel Lijo por no haber evitado "la alteración y destrucción del Sitio de Memoria de la Brigada Aérea Militar de El Palomar". Avruj había reconocido, ante la jueza federal de San Martín Martina Forns, a cargo del amparo presentado por los vecinos reunidos en Stop FlyBondi, que la base aérea estaba protegida por la legislación de la que él mismo es la autoridad de aplicación.

10 Claudio Avruj planteó en reiteradas ocasiones que "en la Argentina hubo una apropiación de la agenda de derechos humanos y se dejó de lado la agenda de derechos económicos, culturales y sociales del presente” (La Capital, 06-03-2016). Con lo cual, sostiene, "tenemos que dar un paso adelante, que si realmente algo aprendimos de lo que nos pasó hace 40 años es tener que trabajar fuertemente con una agenda completa de derechos humanos” (Página 12, 09-05-2016).

11 Nota realizada en el Diario La Nación, 26-03-2016.

12 Ver nota completa en La Politica Online, 14-01-2016.

13 Para Highton, Rosenkrantz y Rosatti, Muiña puede ser beneficiado con la ley 24.390, sancionada en 1994 para establecer plazos para la prisión preventiva. Esa ley estuvo en vigencia entre 1994 y 2001 : mucho después de las privaciones ilegales de la libertad en las que estuvo involucrado Muiña y mucho antes de que fuera detenido, procesado y condenado. Ricardo Lorenzetti y Juan Carlos Maqueda votaron en disidencia y sostuvieron que ningún tipo de amnistía puede aplicarse a delitos de lesa humanidad.

14 Para profundizar: http://revistaanfibia.com/cronica/los-cruzaras-en-la-calle/ y https://www.pagina12.com.ar/208789 -la-historia-secreta-del-fallo-del-2-x-1

15 Los autodenominados "Carapintadas" fueron un grupo de militares del Ejército Argentino, que realizaron una serie de levantamientos militares contra los gobiernos constitucionales de Raúl Alfonsín y Carlos Menem. Aldo Rico integró este grupo y desfiló en el acto del 9 de julio de 2019.

16 En el año 2017, por problemas de mantenimiento edilicios, el Museo debió cerrar su sede ubicada en el centro de la Ciudad de Buenos Aires, en la calle Montevideo, para trasladarse de forma transitoria a la sede del Seminario Rabínico en el barrio de Belgrano. Durante los últimos dos años llevaron a cabo una muestra en este espacio y continuaron con su labor museal mientras se llevó a cabo la refacción del edificio y la creación de una nueva muestra central, que tiene fecha de inauguración el 1 de diciembre de 2019.

17 Bourdieu, P. (1977). La ilusión Biográfica. Razones prácticas. España, Anagrama, Colección Argumentos.

18 Rubén Beraja es ex titular de la DAIA, ex presidente del Banco Mayo y fue imputado en la causa AMIA. Durante los años noventa fue un referente dentro de un sector de la comunidad judía local y durante un breve período fue presidente del Museo del Holocausto (1998).

19 https://www.infobae.com/vidriera/2018/10/30/una-noche-para-no-olvidar-44-fotos-de-la-presentacion-de-la-remo delacion-del-museo-del-holocausto/

$20 \mathrm{Al}$ respecto, se han desatado una serie de polémicas que aún están en desarrollo https://hyperallergic.com/526099/naz i-memorabilia-slated-for-exhibition-are-mostly-modern-forgeries-experts-say/

21 Ver un ejemplo en la nota de Diario Perfil, 12-9-2017.

22 La International Holocaust Remembrance Alliance (IHRA) es una organización intergubernamental creada en 1998, conformada por más de treinta Estados cuyo objetivo es luchar contra los actos de intolerancia y discriminación que puedan conducir a tragedias como las vividas por la humanidad en el siglo XX. Para esto asume el compromiso de abordar la temática del Holocausto desde una triple perspectiva: la educación, la rememoración y la investigación. Argentina es miembro desde la suscripción a la Declaración de Estocolmo en el año 2000. 
23 Se puede acceder a este material a través de la página http://www.bnm.me.gov.ar/giga1/documentos/EL005251.pdf

24 Todos estos materiales se encuentran online. Ver por ejemplo http://repositorio.educacion.gov.ar:8080/dspace/bitst ream/handle/123456789/55779/Holocausto.\%20Preguntas.pdf?sequence=1 o http://www.bnm.me.gov.ar/giga1/do cumentos/EL006319.pdf

25 Algunos de ellos fueron la Red Internacional de Estudios para el Genocidio de UNESCO, Escuela Internacional para el Estudio del Holocausto-Yad Vashem, The Anne Frank House, La Casa de la Conferencia de Wannsee, entre otros.

26 Durante el período en el cual Mauricio Macri fue Jefe de Gobierno de la Ciudad de Buenos Aires se creó la Plaza de Homenaje a las Víctimas del Holocausto-Shoá nombrada anteriormente en el artículo. Se encuentra emplazado en las avenidas del Libertador e Intendente Bullrich. 